Egyptian

Orthodontic Journal

\title{
ASSESSMENT OF THE SKELETAL MATURATION OF CERVICAL VERTEBRAE AND HAND-WRIST IN RELATION TO CHRONOLOGICAL AGE AMONG A SAMPLE OF EGYPTIAN ADOLESCENTS
}

\author{
Hanan A Ismail* Wafaa Essam** \\ Maha Mahmoud ${ }^{\star \star *}$ Abir Sheta***
}

ABSTRACT

The aim of the study was to assess the relation between the three maturity indicators (CVMI, MP3, SMI) and the chronologic age in Egyptian adolescents. Lateral cephalograms and hand-wrist radiographs of 20 females and 15 males ranging from ages 9 to14 years were collected. The cervical vertebrae (C2, C3, and C4) outlines were traced from the lateral cephalograms and analyzed using the CVMI according to the method used by Hassel and Farman and the hand wrist MP3 indicators and Fishman's SMI indicators were used to assess the skeletal maturity of the subject. Results showed a strong correlation between the three methods of maturity indicators, however the correlation was stronger in the female sample. The chronological age was correlated with the maturity indicators except with Fishman's SMI stages in males. Results also showed that males tend to show early stages of maturity indicators in this age group however females showed all stages of maturity in this age group (9-14). It was concluded that females tend to achieve higher percentage of their skeletal growth than

\footnotetext{
* Assistant Prof. of Orthodontics , Faculty of Dentistry, Alexandria University *** Lecturer of Community Dentistry, Faculty of Dentistry, Alexandria University

**** Lecturer of Oral medicine, Periodontology ,Diagnosis and Radiology, Faculty of Dentistry, Alexandria University

***** Lecturer of Forensic Medicine, Faculty of Medicine, Alexandria University
} 
Egyptian

Orthodontic Journal

males especially before 11.5 years and $\mathcal{M} 3$ maturity indicators are more informative of the skeletal maturity in the Egyptian females. CVMI are more informative for the Egyptian males skeletal maturity.

\section{INTRODUCTION}

The clinical importance of evaluating skeletal maturation has long been recognized by the health profession. Skeletal age refers to the degree of development of ossification of the bone which is important in dentofacial orthopedics. Sometimes the whole treatment plan depends on the growth factor. Growth, particularly during puberty, is of value in the treatment of skeletal deviations in the maxilla and the mandible ${ }^{(1,2)}$. A strong correlation has been found between facial growth particularly mandibular changes and increase in statural height.

Individual variations in timing, duration and velocity of growth, skeletal age assessment is essential and helpful in formulating viable orthodontic treatment plans. During growth every bone goes through a series of changes that can be seen radiologically. The sequence of change is relatively constant for a given bone in every person but the timing of the changes varies because each person has his or her own biological clock. Mappes et al indicated that predominant ethnic origin, climate, nutrition, socioeconomic level and urbanization are causative factors of these racial variations ${ }^{(3)}$.

Scientific estimation of an individual's age is extremely important for forensic science. Age estimation help in both civil and criminal cases; such as consent, kidnapping, rape, and marriage status. Up to 18 years, it is preferable to use skeletal age estimation as a predictor ${ }^{(4)}$. The hand and wrist radiograph is considered to be the most standardized method of skeletal assessment. Assessment of skeletal maturation using hand and wrist radiograph as an index based upon time and sequence of appearance of carpal bones and certain ossification events has been reported by many investigators.

Fishman $1995^{(5)}$ developed a system of skeletal maturation assessment based on six anatomic sites located on the thumb, third finger, fifth finger and radius. He described 11 adolescent skeletal maturity indicators on the six sites predicting the entire period of adolescence and reported the percentage of growth completed corresponding to each maturity indicator.

Recent studies showed that the cervical vertebrae have different shapes at each skeletal development level. During growth every bone goes through a series of changes that can be seen radiologically. In 1972, Lamparski stated that

Volume 33 - June 2008 
the cervical vertebrae were as statistically and clinically reliable in assessing skeletal age as the hand and wrist technique ${ }^{(6,7)}$. Many researchers have reported that the cervical vertebrae method is a reliable skeletal age indicator. Racial variations in the relationships were also suggested ${ }^{(1,3,4)}$.

Hassel and Farman used cervical as maturity indicators by assessing the lateral profile changes of the second, third and fourth vertebrae. The cervical vertebrae maturity indicators were evaluated against the skeletal maturation index established from the hand and wrist radiograph by Fishman. The method has the advantage of eliminating the need for an additional radiographic exposure since the vertebrae are recorded in the lateral cephalogram taken as a pretreatmant record ${ }^{(1)}$.

Hagg and Taranger ${ }^{(8)}$ analysed yearly hand and wrist radiographs of individuals from age 6 to 18 years and studied the ossification of the adductor sesamoid (S) of the thumb, the middle and distal phalanges of the third finger(MP3and DP3) and the distal epiphysis of the radius. Kansal and Rajagopal $^{(9,10)}$ modified the MP3 indicators further and compared them to the cervical vertebrae maturation indices (CVMI) as described by Hassel and Farman. They used periapical radiographic films to study the MP3 stages of the middle phalanx of the third finger to reduce radiation exposure. Their study proved that using the periapical film to record the MP3 stages is an accurate, simple, practical and economical growth indicator for making decisions on treatment timing.

The aim of this study is to investigate the relationship between chronologic age and maturation stage of cervical vertebrae and analyzing the hand and wrist radiograph using MP3 indicators and Fishman's stages of maturity indicators in Egyptian adolescents.

\section{Material \& Methods}

\section{Study Sample and Design}

The present research is a descriptive, retrospective study design. The study sample was derived from the lateral cephalometric, as well as the hand-wrist $\mathrm{x}$ rays of 35 Egyptian patients coming for orthodontic treatment (20 females and 15 males), age ranging from 9 to 14 years old.

\section{Selection Criteria}

(1) no systemic diseases that could affect the general development.

(2) no history of orthodontic treatment yet.

(3) lateral cephalometric and hand and wrist radiographs available with high clarity. 
The cephalometric and the hand and wrist radiographs were collected and traced.

Method of tracing the films:

1. The radiographic films were covered on one side with the matte acetate tracing paper.

2. The tracings of the films were done using $4 \mathrm{H}$ lead pencil.

3. The phalanges of the third and fifth fingers were traced along with the adductor sesamoid(S) bone of the first finger if present and the distal epiphysis and metaphysis of the radius.

In the lateral cephalograms, three parts of the cervical vertebrae were traced; these entities include the dens odontoid process - C2, body of the third cervical vertebrae - C3 and the body of the fourth cervical vertebrae - C4. The tracings were traced by a single operator and scored.

The cervical vertebral analysis was assessed by the cervical vertebral maturation index (CVMI) method as determined by the Hassel and Farman method which assess maturational changes on the second, third, and fourth cervical vertebrae. ${ }^{(1)}$
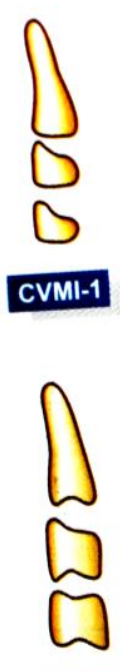

CVMI-4

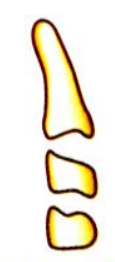

CVMI-2

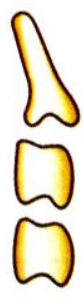

CVMI-5
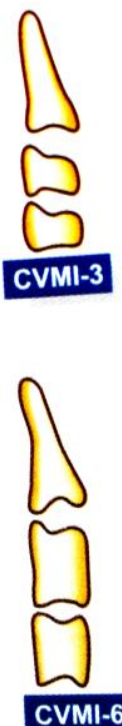

CVMI Stages (Fig. 1) 
Egyptian

Orthodontic Journal

CVMI-1: Initiation stage of cervical vertebrae

1- C2, C3, and C4 inferior vertebral body borders are flat.

2- Superior vertebral borders are tapered from posterior to anterior (wedge shape)

3- 80-100 percent of pubertal growth remains.

CVMI-2: Acceleration stage of cervical vertebrae.

1- Concavities are developing in the lower border of $\mathrm{C} 2$ and $\mathrm{C} 3$.

2- Lower border of $\mathrm{C} 4$ vertebral body is flat.

3- $\mathrm{C} 3$ and $\mathrm{C} 4$ are more rectangular in shape.

4- 65-85 percent of pubertal growth remains.

CVMI-3: Transition stage of cervical vertebrae.

1- Distinct concavities are seen on the lower borders of $\mathrm{C} 2$ and $\mathrm{C} 3$.

2- Concavity is developing on the lower border of $\mathrm{C} 4$.

3- $\mathrm{C} 3$ and $\mathrm{C} 4$ are rectangular in shape.

4- 25-65 percent of pubertal growth remains.

CVMI-4: Deceleration stage of cervical vertebrae.

1- Distinct concavities are seen on the lower borders of $\mathrm{C} 2, \mathrm{C} 3$ and $\mathrm{C} 4$.

2- $\mathrm{C} 3$ and $\mathrm{C} 4$ are nearly square in shape.

3- Approximately $25 \%$ of pubertal growth remains.

CVMI-5: Maturation stage of cervical vertebrae.

1- Accentuated concavities of $\mathrm{C} 2, \mathrm{C} 3$ and $\mathrm{C} 4$ inferior vertebral body borders are observed.

2- $\mathrm{C} 3$ and $\mathrm{C} 4$ are square in shape.

3- 5-10 percent of pubertal growth remains.

CVMI-6: Completion stage of cervical vertebrae.

1- Deep concavities are present in $\mathrm{C} 2, \mathrm{C} 3$ and $\mathrm{C} 4$ inferior vertebral body borders.

2- $\mathrm{C} 3$ and $\mathrm{C} 4$ are greater in height than in width.

3- Pubertal growth is complete. 

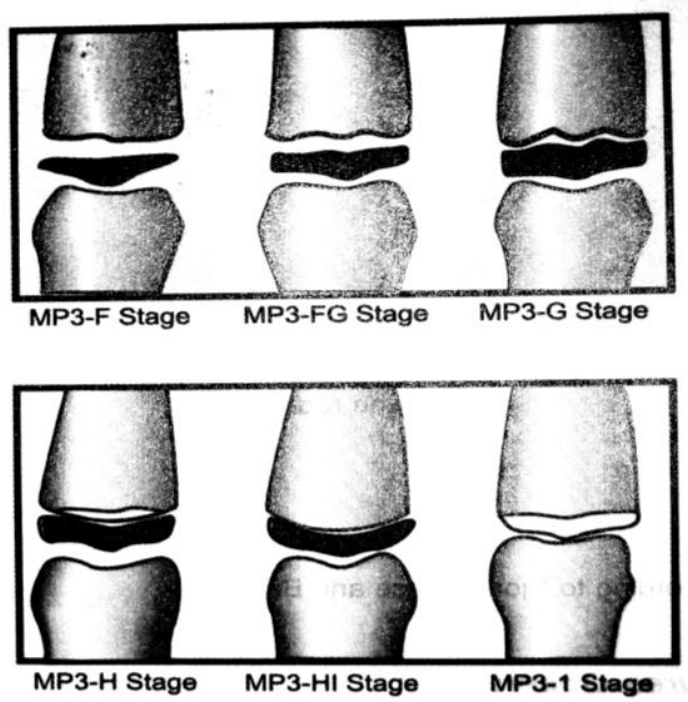

Fig. $2^{(9)}$

Hand and wrist radiographs were evaluated according to Kansal and Rajagopal ${ }^{(9,10)}$ where the middle phalanx of the third finger (MP3) was assessed and the stage of maturation identified according to the following stages(Fig2)

MP3-F stage: Start of the curve of pubertal spurt.

1- Epiphysis is as wide as metaphysis.

2- Ends of epiphysis are tapered and rounded.

3- Metaphysis shows no undulation.

4- Radiolucent gap (representing cartilaginous epiphyseal growth plate) between epiphysis and metaphysis is wide.

MP3-FG stage: Acceleration of the curve of pubertal growth spurt.

1- Epiphysis is as wide as metaphysis.

2- Distinct medial and/or lateral border of the epiphysis forms a line of demarcation at right angle to the distal border.

3- Metaphysis begins to show slight undulation.

4- Radiolucent gap between metaphysis and epiphysis is wide. 
MP3-G stage: Maximum point of pubertal growth spurt.

1- Sides of the epiphysis have thickened and cap its metaphysis, forming sharp distal edge on one or both sides.

2- Marked undulations in the metaphysis give it "cupid's bow" appearance.

3- Radiolucent gap is moderate.

MP3-H stage: Deceleration of the curve of pubertal growth.

1- Fusion of epiphysis and metaphysis begins.

2- One or both sides of the epiphysis form obtuse angle to distal border.

3- Epiphysis is beginning to narrow.

4- Slight convexity is seen under central part of the metaphysis.

5- Radiolucent gap is narrower.

MP3-HI stage: Maturation of the curve of pubertal growth spurt.

1- Superior surface of the epiphysis shows smooth concavity.

2- Metaphysis shows smooth convexity almost fitting in the reciprocal concavity of the epiphysis.

3- No undulation is present in the metaphysis.

4- Radiolucent gap is insignificant.

MP3-I stage: End of pubertal growth spurt.

1- Fusion of epiphysis and metaphysis is complete.

2- No radiolucent gap exists between metaphysis and epiphysis.

3- Dense, radiographic epiphyseal line forms integral part of proximal portion of middle phalynx.

Hand and wrist were also evaluated according to Fishmans ${ }^{(5)}$ maturity indicators and SMI stage identified as follows: (Fig 3)

Width of epiphysis as diaphysis

1- Third finger-proximal phalanx.

2- Third finger-middle phalanx.

3- Fifth finger-middle phalanx.

Ossification

4- Adductor sesamoid of the thumb. 
Capping of epiphysis

5- Third finger-distal phalanx.

6- Third finger-middle phalanx.

7- Fifth finger-middle phalanx.

Fusion of epiphysis and diaphysis

8- Third finger-distal phalanx.

9- Third finger-proximal phalanx.

10- Third finger-middle phalanx.

11- Radius.

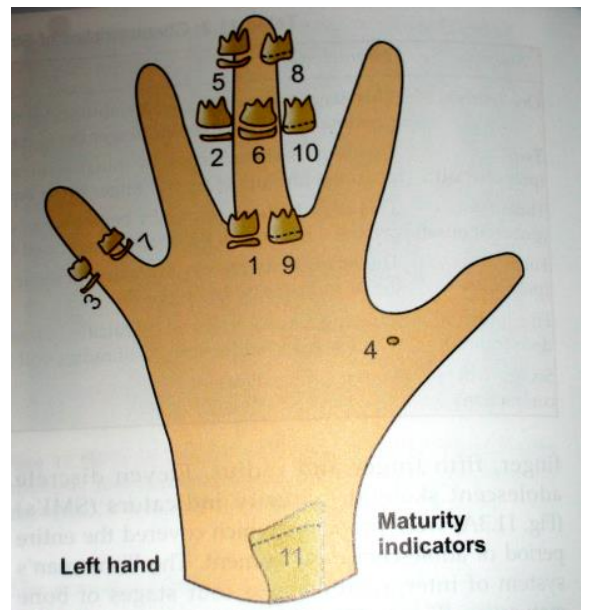

Fig. $3^{(9)}$

\section{Statistical Analysis}

Descriptive statistics were displayed as mean \pm SD for quantitative variables and numbers and percents for qualitative variables. Correlation between chronological age and the different staging systems as well as among the different staging systems was done using Spearman rho. Comparison of the different staging systems between younger (9-11.5) and older age groups (>11.5- 14 years) was done using chi square. Bar graphs were used for graphical presentation. Significance was set at $5 \%$ level.

Reliability was done by rescoring the same radiographs after one week interval. Intraexaminer error was found negligible. 
Egyptian

Orthodontic Journal

RESULTS

Table 1: Showing sample description

\begin{tabular}{|l|c|c|c|}
\hline & N $(\%)$ & $\begin{array}{c}\text { Age } \\
\text { Min- Max }\end{array}$ & Mean \pm SD \\
\hline Male & 15 & $9-14$ & $11.2 \pm 1.5$ \\
\hline Female & 20 & $9-14$ & $11.6 \pm 1.4$ \\
\hline Total & 35 & $9-14$ & $11.4 \pm 1.4$ \\
\hline
\end{tabular}

Data in Table 1 show the description of the study sample which constituted of a total of 35 children, 15 males and 20 females with a mean age of $11.4 \pm 1.4$

Table 2: Correlation between age, MP3 stages, CVMI stages and Fishman stages:

\begin{tabular}{|l|c|c|c|c|}
\hline & Age Correlation & MP3 Stages & CVMI Stages & Fishman Stages \\
\hline Total & Rho & 0.82 & 0.88 & 0.72 \\
& P value & $<0.0001^{*}$ & $<0.0001^{*}$ & $<0.0001^{*}$ \\
\hline Male & Rho & 0.62 & 0.86 & 0.49 \\
& P value & $0.02 *$ & $<0.0001^{*}$ & 0.07 \\
\hline Female & Rho & 0.89 & 0.87 & 0.78 \\
& P value & $<0.0001^{*}$ & $<0.0001^{*}$ & $<0.0001^{*}$ \\
\hline
\end{tabular}

Table 2 shows a statistically significant correlation in the whole sample between age and each of MP3, CVMI and Fishman maturation stages. A stronger correlation was detected among females regarding the different assessment methods where Rho value was found to be $0.89,0.87$ and 0.78 compared to $0.62,0.86$ and 0.49 for males respectively.

Table 3: Correlation matrix between three staging methods:

\begin{tabular}{|c|c|c|c|}
\hline \multicolumn{1}{|c|}{ Stages } & & MP3 & Fishman \\
\hline \multirow{2}{*}{ CVMI } & Rho & 0.90 & 0.86 \\
& P value & $<0.0001^{*}$ & $<0.0001^{*}$ \\
\hline \multirow{2}{*}{ MP3 } & Rho & - & 0.87 \\
& P value & $-0001^{*}$ \\
\hline
\end{tabular}

Correlation matrix between three staging methods by sex:

\begin{tabular}{|l|c|c|c|c|c|}
\hline \multirow{2}{*}{ Stages } & & \multicolumn{2}{c|}{ MP3 } & \multicolumn{2}{c|}{ Fishman } \\
\cline { 3 - 6 } & & Male & Female & Male & Female \\
\hline \multirow{2}{*}{ CVMI } & Rho & 0.91 & 0.97 & 0.89 & 0.97 \\
& P value & $<0.0001 *$ & $<0.0001^{*}$ & $<0.0001^{*}$ & $<0.0001^{*}$ \\
\hline \multirow{2}{*}{ MP3 } & Rho & - & - & 0.89 & 0.95 \\
& P value & - & $-0.0001 *$ & $<0.0001^{*}$ \\
\hline
\end{tabular}

Tables 3 show a strong correlation between the three methods of maturity indicators. The correlation was stronger for the female sample.

Volume 33 - June 2008 
Egyptian

Orthodontic Journal

Table4: Distribution of MP3 stages by age

\begin{tabular}{|l|c|c|}
\hline \multirow{2}{*}{\multicolumn{1}{|c|}{ MP3 Stages }} & \multicolumn{2}{|c|}{ Age Groups } \\
\cline { 2 - 3 } & $\mathbf{9 - 1 1 . 5}$ yrs & >11.5- 14 yrs \\
\hline Stage 1 F & $6(31.6)$ & - \\
Stage 2 FG & $11(57.9)$ & $3(18.8)$ \\
Stage 3 G & $2(10.5)$ & $5(31.3)$ \\
Stage 4 H & - & $3(18.8)$ \\
Stage 5 HI & - & $2(12.5)$ \\
Stage 6 I & - & $3(18.8)$ \\
\hline Chi square & \multicolumn{3}{|c}{19.75} \\
P value & \multicolumn{2}{|c}{$0.001 *$} \\
\hline
\end{tabular}

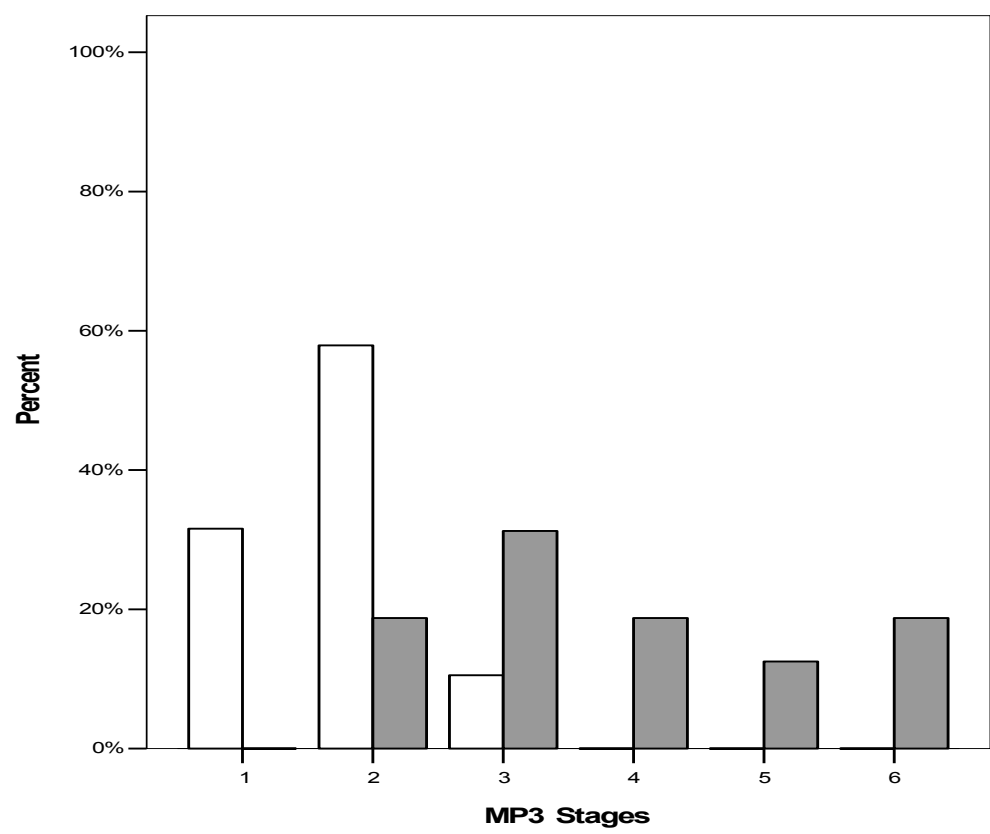

age group $\square$ 9- 11.5 yrs $\square 11.8-14 \mathrm{yrs}$

Data in Table 4 showed the distribution of the MP3 stages among different age groups, where the majority of the children aged 9-11.5 years presented in stage 2 FG $(57.9 \%)$, followed by stage $1 \mathrm{~F}(31.6 \%)$, while the majority of the children aged 11.5-14 years were found in stage $\mathrm{G}(31.3 \%)$. 
Egyptian

Orthodontic Journal

Table 5: Distribution of MP3 stages by age for males:

\begin{tabular}{|l|c|c|}
\hline \multirow{2}{*}{ MP3 Stages } & \multicolumn{2}{|c|}{ Age Groups } \\
\cline { 2 - 3 } & $\mathbf{9 - 1 1 . 5}$ yrs & >11.5- 14 yrs \\
\hline Stage 1 F & $5(50)$ & 0 \\
Stage 2 FG & $5(50)$ & $2(40)$ \\
Stage 3 G & 0 & $1(20)$ \\
Stage 4 H & 0 & $1(20)$ \\
Stage 5 HI & 0 & $1(20)$ \\
Stage 6 I & 0 & 0 \\
\hline Chi square & \multicolumn{2}{|c}{} \\
P value & \multicolumn{2}{|c|}{8.57} \\
\hline
\end{tabular}

Results in Table 5 showed that $50 \%$ of the males aged 9-11.5 years old were found in stage $\mathrm{F}$ and $\mathrm{FG}$, respectively, while none of this age group presented in the following maturation stages. However, $40 \%$ of the males aged 11.5-14 years were found to be in stage FG, while $20 \%$ were found in stages $\mathrm{G}$, $\mathrm{H}$ and $\mathrm{HI}$, respectively. None of the 11.5-14 year-old males presented in stage

Table 6: Distribution of MP3 stages by age for females:

\begin{tabular}{||l|c|c||}
\hline \multirow{2}{*}{ MP3 Stages } & \multicolumn{2}{|c||}{ Age Groups } \\
\cline { 2 - 3 } & $\mathbf{9 - 1 1 . 5}$ yrs & >11.5- 14 yrs \\
\hline Stage 1 F & $1(11.1)$ & 0 \\
Stage 2 FG & $6(66.7)$ & $1(9.1)$ \\
Stage 3 G & $2(22.2)$ & $4(36.4)$ \\
Stage 4 H & 0 & $2(18.2)$ \\
Stage 5 HI & 0 & $1(9.1)$ \\
Stage 6 I & 0 & $3(27.3)$ \\
\hline Chi square & \multicolumn{2}{|c|}{} \\
P value & \multicolumn{2}{|c|}{11.15} \\
\hline
\end{tabular}

Table 6 shows that $66.7 \%$ and $22.2 \%$ of the $9-11.5$ year-old females were found in stages FG and G, respectively, while none of them presented in the following maturation stages. Regarding females aged 11.5-14 years old, 36.4\% were found in stage $\mathrm{G}$, followed by $27.3 \%$ in stage I while only $18.2 \%$ and 9.1\% were found in stages $\mathrm{H}$ and $\mathrm{HI}$, respectively. 
Egyptian

Orthodontic Journal

Table 7: Distribution of CVMI stages by age

\begin{tabular}{|l|c|c|}
\hline \multirow{2}{*}{ CVMI Stages } & \multicolumn{2}{|c|}{ Age Groups } \\
\cline { 2 - 3 } & $\mathbf{9 - 1 1 . 5}$ yrs & >11.5- 14 yrs \\
\hline Stage 1 & $4(21.1)$ & - \\
Stage 2 & $13(68.4)$ & $3(18.8)$ \\
Stage 3 & $2(10.5)$ & $4(25)$ \\
Stage 4 & - & $3(18.8)$ \\
Stage 5 & - & $3(18.8)$ \\
Stage 6 & - & $3(18.8)$ \\
\hline Chi square & \multicolumn{2}{|c|}{19.81} \\
P value & \multicolumn{2}{|c|}{$0.001^{*}$} \\
\hline
\end{tabular}

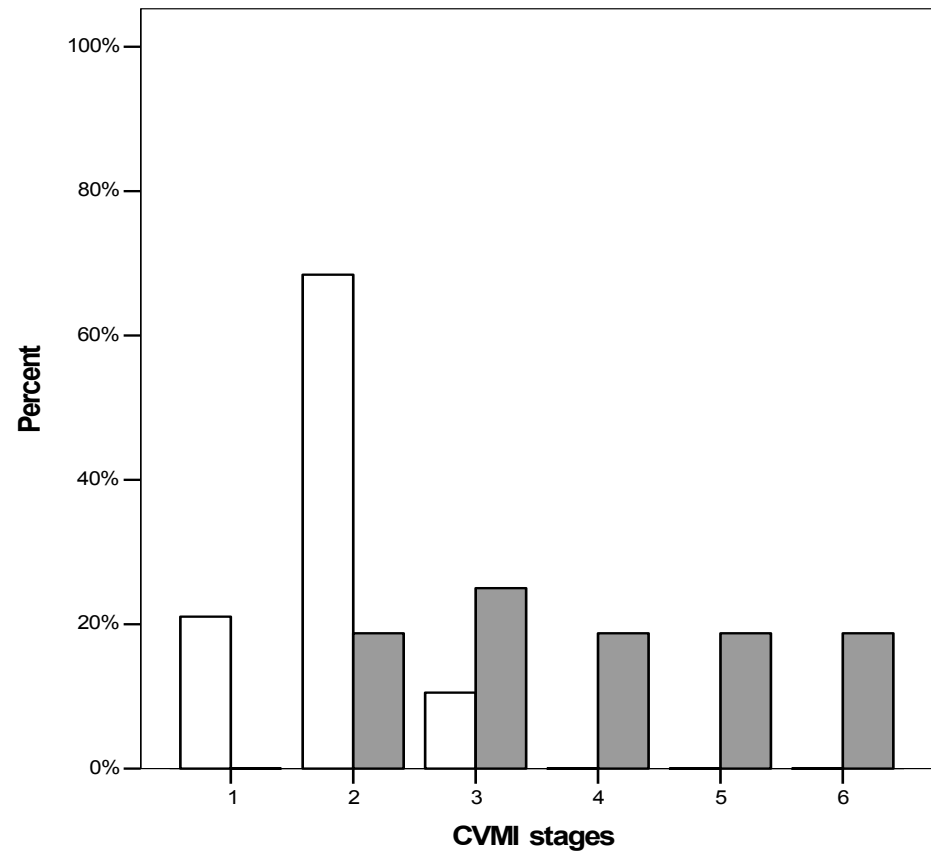

age group

$\square$ 9- $11.5 \mathrm{yrs}$

ㅁ 11.8- $14 \mathrm{yrs}$

Data in Table7 showed that most of the children aged 9-11.5 years old were found in stage 2 CVMI (68.4\%), followed by $21.1 \%$ in stage 1 and $10.5 \%$ in stage 3. Regarding age group 11.5-14 years, the majority of the children presented in stage $3(25 \%)$, while none of them presented in stage 1 . There was a statistically significant difference between the two age groups. 
Egyptian

Orthodontic Journal

Table 8: Distribution of CVMI stages by age for males

\begin{tabular}{|l|c|c|}
\hline \multirow{2}{*}{ CVMI Stages } & \multicolumn{2}{|c|}{ Age Groups } \\
\cline { 2 - 3 } & $\mathbf{9 - 1 1 . 5}$ yrs & >11.5- 14 yrs \\
\hline Stage 1 & $2(20)$ & 0 \\
Stage 2 & $8(80)$ & $1(20)$ \\
Stage 3 & 0 & $1(20)$ \\
Stage 4 & 0 & $2(40)$ \\
Stage 5 & 0 & $1(20)$ \\
Stage 6 & 0 & 0 \\
\hline Chi square & \multicolumn{3}{|c|}{11.00} \\
P value & \multicolumn{2}{|c|}{$0.03^{*}$} \\
\hline
\end{tabular}

Results in Table 8 showed that $20 \%$ of the males aged 9-11.5 years old were found in stage $1 \mathrm{CVMI}$, while $80 \%$ were found in stage 2 and none of this age group presented in the following stages. Regarding age 11.5-14 years, 20\% were found in stages 2,3 and 5 respectively, while $40 \%$ were found in stage 4 and none presented in stages 1 and 6 . There was a ststistically significant difference between the two age groups.

Table 9: Distribution of CVMI stages by age for females

\begin{tabular}{|l|c|c|}
\hline \multirow{2}{*}{ CVMI Stages } & \multicolumn{2}{|c|}{ Age Groups } \\
\cline { 2 - 3 } & 9-11.5 yrs & >11.5- 14 yrs \\
\hline Stage 1 & $2(22.2)$ & 0 \\
Stage 2 & $5(55.6)$ & $2(18.2)$ \\
Stage 3 & $2(22.2)$ & $3(27.3)$ \\
Stage 4 & 0 & $1(9.1)$ \\
Stage 5 & 0 & $2(18.2)$ \\
Stage 6 & 0 & $3(27.3)$ \\
\hline Chi square & \multicolumn{2}{|c}{} \\
P value & \multicolumn{2}{|c}{} \\
\hline
\end{tabular}

Results in Table 9 showed that most of the females at age 9-11.5 years presented in stage $2 \mathrm{CVMI}(55.6 \%)$, while $22.2 \%$ were found in stages 1 and 3 . However, $27.3 \%$ of the 11.5-14 years were found in stages 3 and 6 while $18.2 \%$ presented in stages 2 and 5 and only $9.1 \%$ were found in stage 4 . There was no ststistical significant difference between the two age groups. 
Egyptian

Orthodontic Journal

Table 10: Distribution of Fishman stages by age(SMI):

\begin{tabular}{|l|c|c|}
\hline \multirow{2}{*}{ Fishman Stages } & \multicolumn{2}{|c|}{ Age Groups } \\
\cline { 2 - 3 } & 9-11.5 yrs & >11.5- 14 yrs \\
\hline Stage 1 & - & - \\
Stage 2 & $3(15.8)$ & $1(6.3)$ \\
Stage 3 & $12(63.2)$ & $2(12.5)$ \\
Stage 4 & $2(10.5)$ & $1(6 / 3)$ \\
Stage 5 & - & $1(6.3)$ \\
Stage 6 & $2(10.5)$ & $4(25)$ \\
Stage 7 & - & - \\
Stage 8 & - & $3(18.8)$ \\
Stage 9 & - & - \\
Stage 10 & - & $3(18.8)$ \\
Stage 11 & - & $1(6.3)$ \\
\hline Chi square & \multicolumn{2}{|c}{17.01} \\
P value & \multicolumn{2}{|c}{} \\
\hline
\end{tabular}

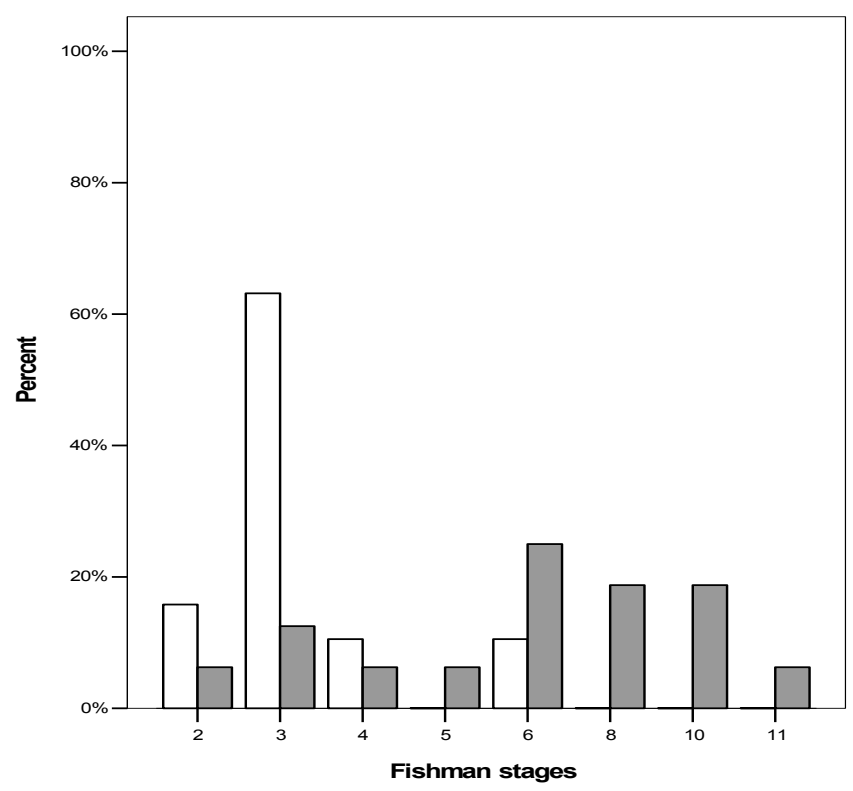

age group

11.8- 14 yrs

Results in Table 10 show that most of the children aged 9-11.5 years were found in stage 3 Fishman (63.2\%), followed by $15.8 \%$ in stage 2 and $10.5 \%$ in stages 4 and 6. On the other hand, most of the children aged 11.5-14 years presented in stage 6 Fishman (25\%), followed $18.8 \%$ in stages 8 and 10 , while only $6.3 \%$ were found in stage 11 . A statistical significant difference was detected between age groups. 
Egyptian

Orthodontic Journal

Table 11: Distribution of Fishman stages by age for males

\begin{tabular}{|l|c|c|}
\hline \multirow{2}{*}{ Age Groups } & \multicolumn{2}{|c|}{ Age Groups } \\
\cline { 2 - 3 } & $\mathbf{9 - 1 1 . 5}$ yrs & $>11.5-14$ yrs \\
\hline Stage 1 & - & 0 \\
Stage 2 & $3(30)$ & $1(20)$ \\
Stage 3 & $7(70)$ & 0 \\
Stage 4 & 0 & $1(20)$ \\
Stage 5 & 0 & 0 \\
Stage 6 & 0 & $2(40)$ \\
Stage 7 & 0 & 0 \\
Stage 8 & 0 & 0 \\
Stage 9 & 0 & 0 \\
Stage 10 & 0 & $1(20)$ \\
Stage 11 & 0 & 0 \\
\hline Chi square & 0 & \\
P value & \multicolumn{2}{|c}{} \\
\hline
\end{tabular}

Data in Table 11 showed that $70 \%$ of the $9-11.5$ year- old males were found in stage 3 Fishman, while $30 \%$ were found in stage 2 . Meanwhile, $40 \%$ of the 11.5-14 year-old boys were found in stage 6, while only $20 \%$ presented in stage 10 and none was found in stage 11 Fishman. A statistically significant difference was detected among males in different age groups.

Table 12: Distribution of Fishman stages by age for females:

\begin{tabular}{|l|c|c|}
\hline \multirow{2}{*}{ Age Groups } & \multicolumn{2}{|c|}{ Age Groups } \\
\cline { 2 - 3 } & $\mathbf{9 - 1 1 . 5}$ yrs & $>11.5-14$ yrs \\
\hline Stage 1 & 0 & 0 \\
Stage 2 & 0 & 0 \\
Stage 3 & $5(55.6)$ & $2(18.2)$ \\
Stage 4 & $2(22.2)$ & 0 \\
Stage 5 & 0 & $1(9.1)$ \\
Stage 6 & $2(22.2)$ & $2(18.2)$ \\
Stage 7 & 0 & 0 \\
Stage 8 & 0 & $3(27.3)$ \\
Stage 9 & 0 & 0 \\
Stage 10 & 0 & $2(18.2)$ \\
Stage 11 & 0 & $1(9.1)$ \\
\hline Chi square & \multicolumn{2}{|c|}{} \\
P value & \multicolumn{2}{|c|}{} \\
\hline
\end{tabular}

Results displayed in Table 12 showed that the majority of 9-11.5 year-old females $(55.6 \%)$ presented in stage 3, while $22.2 \%$ were found in stages 4 and 6 Fishman. Meanwhile, most of the 11.5-14 year-old females $(27.3 \%)$ were found in stage 8 , followed by $18.2 \%$ in stage 10 and $9.1 \%$ in stage 11 Fishman. There was no ststistically significant difference between the two age groups 
Table 13: Comparison between Cervical vertebrae maturation stages and MP3 stages at different chronologic ages

\begin{tabular}{|c|c|c|c|c|c|c|c|}
\hline \multirow{2}{*}{\multicolumn{2}{|c|}{ Age }} & \multicolumn{3}{|c|}{ CVMI } & \multicolumn{3}{|c|}{ MP3 } \\
\hline & & Male & Female & Total & Male & Female & Total \\
\hline \multirow{2}{*}{9} & Stage 1 & $2(66.7)$ & $1(100)$ & $3(75)$ & $2(66.7)$ & $1(100)$ & $3(75)$ \\
\hline & Stage 2 & $1(33.3)$ & 0 & $1(25)$ & $1(33.3)$ & 0 & $1(25)$ \\
\hline \multirow{2}{*}{10} & Stage 1 & 0 & $1(20)$ & $1(14.3)$ & 0 & 0 & 0 \\
\hline & Stage 2 & $2(100)$ & $4(80)$ & $6(85.7)$ & $2(100)$ & $5(100)$ & $7(100)$ \\
\hline \multirow{3}{*}{11} & Stage 1 & 0 & 0 & 0 & $3(50)$ & 0 & $3(33.3)$ \\
\hline & Stage 2 & $6(100)$ & $1(33.3)$ & $7(77.8)$ & $3(50)$ & $1(33.3)$ & $4(44.4)$ \\
\hline & Stage 3 & 0 & $2(66.7)$ & $2(22.2)$ & 0 & $2(66.7)$ & $2(22.2)$ \\
\hline \multirow{3}{*}{12} & Stage 2 & 0 & $2(40)$ & $2(33.3)$ & $1(100)$ & $1(20)$ & $2(33.3)$ \\
\hline & Stage 3 & $1(100)$ & $2(40)$ & $3(50)$ & 0 & $3(60)$ & $3(50)$ \\
\hline & Stage 4 & 0 & $1(20)$ & $1(16.7)$ & 0 & $1(20)$ & $1(16.7)$ \\
\hline \multirow{4}{*}{13} & Stage 3 & 0 & $1(16.7)$ & $1(11.1)$ & $1(33.3)$ & $1(16.7)$ & $2(22.2)$ \\
\hline & Stage 4 & $2(66.7)$ & 0 & $2(22.2)$ & $1(33.3)$ & $1(16.7)$ & $2(22.2)$ \\
\hline & Stage 5 & $1(33.3)$ & $2(33)$ & $3(33.3)$ & $1(33.3)$ & $1(16.7)$ & $2(22.2)$ \\
\hline & Stage 6 & 0 & $3(50)$ & $3(33.3)$ & 0 & $3(50)$ & $3(33.3)$ \\
\hline \multirow{2}{*}{\multicolumn{2}{|c|}{$\begin{array}{l}\text { Chi square } \\
\text { P value }\end{array}$}} & 38.89 & 34.25 & 53.56 & 18.86 & 43.81 & 46.71 \\
\hline & & $0.001 *$ & $0.02 *$ & $<0.0001^{*}$ & 0.28 & $0.002 *$ & $0.001 *$ \\
\hline
\end{tabular}

Table 14: Fishman's maturity stages at various chronologic ages

\begin{tabular}{|c|l|c|c|c|}
\hline \multicolumn{2}{|c|}{ Age } & \multicolumn{3}{c|}{ Fishman } \\
\cline { 2 - 5 } \multicolumn{2}{|c|}{} & Male & Female & Total \\
\hline 9 & Stage 3 & $3(100)$ & $1(100)$ & $4(100)$ \\
\hline & Stage 2 & $1(50)$ & 0 & $1(14.3)$ \\
& Stage 3 & $1(50)$ & $4(80)$ & $5(71.4)$ \\
& Stage 4 & 0 & $1(20)$ & $1(14.3)$ \\
\hline 11 & Stage 2 & $3(50)$ & 0 & $3(33.3)$ \\
& Stage 3 & $3(50)$ & 0 & $3(33.3)$ \\
& Stage 4 & 0 & $1(33.3)$ & $1(11.1)$ \\
& Stage 5 & 0 & 0 & 0 \\
& Stage 6 & 0 & $2(66.7)$ & $2(22.2)$ \\
\hline 12 & Stage 3 & 0 & $2(40)$ & $2(33.3)$ \\
& Stage 4 & $1(100)$ & 0 & $1(16.7)$ \\
& Stage 5 & 0 & 0 & 0 \\
& Stage 6 & 0 & $2(40)$ & $2(33.3)$ \\
& Stage 7 & 0 & 0 & 0 \\
& Stage 8 & 0 & $1(20)$ & $1(16.7)$ \\
\hline 13 & Stage 5 & 0 & $1(16.7)$ & $1(11.1)$ \\
& Stage 6 & $2(66.7)$ & 0 & $2(22.2)$ \\
& Stage 7 & 0 & 0 & 0 \\
& Stage 8 & 0 & $2(33.3)$ & $2(22.2)$ \\
& Stage 9 & 0 & 0 & 0 \\
& Stage 10 & $1(33.3)$ & $2(33.3)$ & $3(33.3)$ \\
& Stage 11 & 0 & $1(16.7)$ & $1(11.1)$ \\
\hline Chi square & 33.21 & 29.40 & 38.65 \\
P value & $0.007 *$ & 0.21 & 0.09 \\
\hline
\end{tabular}


Results in Table 14 show that $100 \%$ of the males and females at age 9 were found in stage 1 Fishman, while $50 \%$ of the males and $80 \%$ of the females were found in stage 3 at age 10. At age 12, none of the males and $40 \%$ of the females were found in stage 3, while $100 \%$ of the males and none of the females were found in stage 4 Fishman. Similarly, $20 \%$ of the males and $30 \%$ of the females at age 13 presented in stage 5 - 11Fishman.
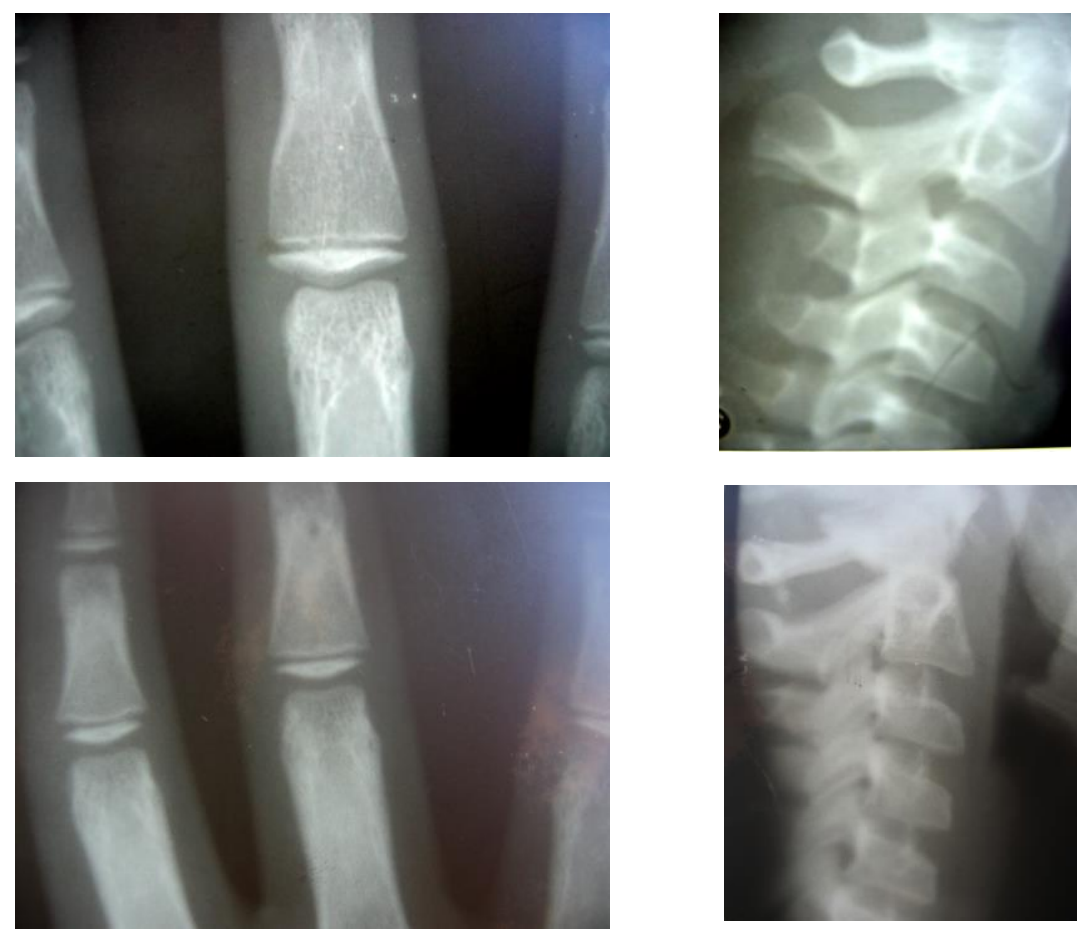

Hand wrist $x$ ray of a male showing MP3 stage FG. Cephalometric $x$ ray of the same patient shows CVMI 3. The lower $\mathrm{x}$ rays shows a another male having MP3 stage F and CVMI 2.

\section{DISCUSSION}

The hand-wrist radiograph has been used classically to determine the level of skeletal maturation of a child. Recently a new method for estimating the skeletal maturity from the cervical vertebrae present in the lateral cephalometric radiograph has been introduced to avoid extra radiation exposure ${ }^{(1,10)}$. 
Egyptian

Orthodontic Journal

The present study was undertaken with the aim to correlate the validity of cervical vertebrae as maturity indicators with the chronologic age and handwrist maturity indicators. Observations of changes in the bones of hand wrist using the MP3 indicators and Fishman's SMI method with the cervical vertebrae maturity indicators (CVMI) were also used in order to be evaluated among Egyptians. An age group of 9-14 years was chosen because males and females have their maximum circumpubertal growth spurt during this period. Adolescent spurt has been recognized as an extremely active period of accelerated growth.

On average, pubertal growth spurt begins at the age of 10 years in girls and 12 years in boys ${ }^{(11)}$; so the total sample was separated into males and females and the age range was selected 9-14 to offer the best opportunity to accomplish the objectives of orthodontic treatment in the shortest time.

There was a significant correlation between the chronologic age and the CVMI and MP3 stages of the hand wrist in both males and females. However when using Fishmans stages of skeletal maturity the chronologic age was correlated in the total sample and in females only. In males there was no significant correlation between the chronologic age and the SMI stages of Fishman which may be due to the small sample size of males compared to the SMI stages (11 stages) or due to the late skeletal maturity in males. There was a significant correlation between the cervical vertebral maturation stages and the hand wrist bone age in both the MP3 and Fishman stages in the total sample, however a stronger correlation was present between CVMI and MP3 maturity indicator(Rho .90)in the total sample. Therefore either method can be used to determine the maturity stage of the growing subject. The SMI indicators and the MP3 were also strongly correlated (Rho .87). This high correlation agrees with other studies which found significant correlation between the cervical vertebrae maturity indicators and hand and wrist maturity indicators ${ }^{(12)}$.

Concerning each sex group the three maturity indicators were highly correlated, however the correlation was stronger in females. This may be attributed to the fact that males mature later than females.

The CVMI gives the percentage of growth remaining. The shape of vertebral bodies $\mathrm{C} 3$ and $\mathrm{C} 4$ changed from wedge shaped to rectangular to square to greater in dimension vertically than horizontally, as skeletal maturity progressed. The inferior vertebral bodies were flat when immature and became concave when mature. In the study sample the age range between 9 to 11.5 years coincided with stages CVMI 1,2and3 with the majority of the sample in stage 2; that is the onset and peak of pubertal growth according to Kansal and 
Rajagopal ${ }^{(10)}$, on the other hand age between 11.5 and 14 years coincided with CVMI 2 to 6 with the majority in stages 4,5 and 6 , that is deaccaleration and end of pubertal growth. When separating males from females, males tended to show cervical maturation later as CVMI 1 and 2 coincided with ages from 9 to 11.5 and ages above 11.5 coincided with CVMI 2 to 5. Females between 9 to 11.5 showed CVMI 1,2 and 3 and ranging from stages 2 to 6 above that age. This shows that the peak of pubertal growth (stage 3)can occur in girls bellow 11.5 years but not in boys as they mature later. This agrees with previous studies reporting that females develop changes in cervical vertebrae earlier than males ${ }^{(2,4,11,13)}$.

It is also obvious that some females mature later and still show active growth in the post pubertal period. This agrees with the study done by Aboul Azm et al who investigated the growth of the cervical vertebrae longitudinally in female subjects and concluded that post pubertal growth in female subjects should be put in consideration when planning orthodontic treatment ${ }^{(15)}$.

There was a statistical significant difference between the two age groups concerning the CVMI maturity stages in males only, but not in females, that it is CVMI are more indicative of the skeletal maturity in males. This agrees with the study done by Ragini ${ }^{(12)}$ where he found the CVMI less reliable for females especially at 12 years of age. He recommended that the CVMI to be used for males only.

The use of the MP3 maturity indicators from the hand wrist radiograph was relatively simple. Stages F, FG or G (onset and peak of pubertal growth) coincided with ages before 11.5 years. After 11.5 years stages FG to I were seen. The difference between the age groups was statistically significant in relation to the MP3 stages in the total sample. The male sample showed stages F and FG (onset of pubertal growth) from ages 9 to 11.5 years, above 11.5 years 2 males showed FG stage and the rest 1 male $\mathrm{G}$ stage, 1 male $\mathrm{H}$ and 1 male $\mathrm{HI}$ stage, however, the difference between the age groups was not significant. This is probably due to the fact that males mature later than females. The females also showed more advanced stages related to their chronologic age and the difference between the age groups was significant. Furthermore, some females showed some active growth remaining after the age of 13 (stages $\mathrm{H}$ and $\mathrm{HI}$ ). On the other hand, males at the age of 13 showed stages $\mathrm{G}$ and $\mathrm{H}$; that is later maturity than girls. Females showed a statistical significant difference in the MP3 indicators between the two age groups however the males did not. Therfore, the MP3 indicators are more indicative of the Egyptian female maturity. 
Fishman's maturity indicators were also used in this study as he used four stages of bone maturation to show 11 stages of maturity indicators to cover the entire period of adolescent development ${ }^{(5)}$. Males before 11.5 years corresponded to SMI stages 2and 3 that is no ossification of adductor sesamoid and they haven't reached the peak of pubertal growth yet. After 11.5 years only one male didn't have the sesamoid bone while the rest of the sample $(80 \%)$ were at stage 4 or above. There was a significant difference between the two age groups of the male sample. The female sample showed stages 3,4 and 6 before 11.5 years, $44.4 \%$ of the female sample showed ossification of the adductor sesamoid at this early age. After 11.5 years $18.2 \%$ of the sample didn't have the adductor sesamoid while the rest of the sample corresponded to advanced SMI stages. However there was no significant difference between the two age groups in the female sample, which means that the females showed more random stages of SMI.

When comparing each chronologic age (tables 13,14) to CVMI stages and MP3 stages, there was a statistically significant difference except for the MP3 maturity indicators for males. However Fishman's SMI were significant only for the male sample.

Skeletal maturation being a continuous process is categorized by distinct continuous events; so it is difficult to differentiate borderline cases.

\section{From the previous study we conclude:}

1- Females are ahead of males at all levels of skeletal maturity, indicating early age of maturation development in females.

2- Females tend to achieve higher percentage of their skeletal growth than males especially before 11.5 years.

3- MP3 maturity indicators are more informative of the skeletal maturity in the Egyptian females.

4- CVMI are more informative for the Egyptian males skeletal maturity than other maturity indicators.

5- CVMI can substitute the hand wrist to assess skeletal maturity for Egyptian adolescents.

\section{REFERENCES}

1- Hassel B, Farman AG. Skeletal maturation evaluation using cervical vertebrae. Am J Orthod Dentof Orthop ; 107:58-66, 1995.

2- Ozer T, Kama JD, Ozer SY. A practical method for determining pubertal growth spurt. Am J Orthod Dentof Orthop ;130(2):131-e1-13,2006. 
3- Cameriere R, Ferante L, MIrtella D, Cingolani M. Carpals and epiphysis of the radius and ulna as age indicators. Int J Legal Med; 120(3):143-6,2006.

4- Kullman L. Accuracy of two dental and one skeletal age estimation method in Swedish adolescents. Forensic Science Int;75:225-36,1995.

5- Fishman LS. Radiographic evaluation of skeletal maturation (a clinically oriented method based on the hand wrist films). The Angle Orthod;52:88-112,1982.

6- Lamparski DG. Skeletal age assessment utilizing cervical vertebrae (master thesis) University of Pittsburgh; 1972. Link from ref.7

7- Caldas MP et al. Use of cervical vertebral dimensions for assessment of children growth. J Applied Oral Science; 15(2),2007

8- Hagg V, Taranger J. Maturation indicators and pubertal growth. Am J Orthod; 82:2299-309,1982.

9- Singh G. Textbook of orthodontics. First edition 2004,Jaypee Brothers Medical Publishers (P) LTD New Delhi

10- Kansal S, Rajagopal R. A comparison of modified MP3 stages. J Clinical Orthod ; 36:398, 2002.

11- Raman PS, Palma JC, Otco MD, Nevado E. Skeletal maturation determined by cervical vertebrae development. European J Orthod ; 24:303-311,2002.

12- Kamal M, Ragini, Goyal S. Comparative evaluation of hand wrist radiographs with cervical vertebrae for skeletal maturation in 10-12 years old children. J of Indian Society of Pedpdontics and Preventive dentistry; 24:127-135, 2006.

13- Flores Mir $\mathrm{C}$ et al. Correlation of skeletal maturation stages determined by cervical vertebrae and hand wrist evaluations. The Angle Orthod; 76(1):1-5, 2005.

14- Uysal T. Chronologic age and skeletal maturation of the cervical vertebrae and hand wrist: Is there a relationship. Am J Orthod Dentofac Orthop;130(5):622-28,2006.

15- Aboul Azm SF, Abd Rabbo AY, El Sakhawy M. A longitudinal study of the cervical vertebral growth. Egyptian Orthod J; 16, Dec:1-13,1999. 